\title{
The College Wage Premium and the Expansion of Higher Education in the UK*
}

\author{
Ian Walker \\ ian.walker@lancs.ac.uk \\ Yu Zhu \\ University of Kent, Canterbury CT2 7NZ, England \\ y.zhu-5@kent.ac.uk
}

Lancaster University Management School, Lancaster LA1 4YX, England

\begin{abstract}
This paper reports estimates of the UK "college premium" for young graduates across successive cohorts from large cross-section datasets for the UK pooled from 1994 to 2006-a period when the higher education participation rate increased dramatically. The growth in relative labour demand suggests that graduate supply considerably outstripped demand which ought to imply a fall in the premium. We find no significant fall for men and even a large, but insignificant, rise for women. Quantile regression results reveal a fall in the premium only for men in the bottom quartile of the distribution of unobserved skills.
\end{abstract}

Keywords: Human capital; higher education; college premium

JEL classification: I20; J30

\section{Introduction}

The proportion of graduates in the UK labour force has risen from $9 \%$ to more than $13 \%$ over the 15 years to 2006 . According to official statistics, the proportion of college-age young adults who go to university (referred to as "college" in the US literature) had been stable at approximately $15 \%$ for males and $13 \%$ for females from the early 1970 s to the late 1980 s, but rose dramatically to become approximately $30 \%$ for males and $35 \%$ for females from the mid-1990s onwards. OECD (2007) shows that between 1988 and 1996, while US higher education (HE) participation rose by only $15 \%$, HE participation in the UK rose by $93 \%$. UK official estimates for $2005 / 2006$, albeit using a changed definition of participation according to DfES (2007),

\footnotetext{
* We are grateful to the Department for Education and Skills (DfES) in England and Wales, and Scottish Enterprise for funding earlier research on which this paper builds. Financial support from the Leverhulme Trust is gratefully acknowledged. The Labour Force Survey data were provided by the Economic and Social Research Council's Data-Archive at the University of Essex and is used with permission. The comments of two anonymous referees have been extremely useful but the usual disclaimer applies.
}

(C) The editors of the Scandinavian Journal of Economics 2008. Published by Blackwell Publishing, 9600 Garsington Road, Oxford, OX4 2DQ, UK and 350 Main Street, Malden, MA 02148, USA. 
suggest that close to $40 \%$ of young men and close to $50 \%$ of young women are now entering university. This has been a sharp change in a very short period of time. ${ }^{1}$ The UK change arose largely because of the relaxation of limits on higher education student recruitment at the same time as a large reduction in the amount of Treasury funding provided per student. $\mathrm{HE}$ institutions responded to these reductions in funding by expanding the numbers of students admitted.

The central question which we pose here is: how did this sharp increase in the supply of UK graduates ${ }^{2}$ affect the college wage premium? The question has wide relevance since many other countries have experienced substantial expansions of higher education. ${ }^{3}$ Of course, the question is difficult to answer, not least because the expansion in supply of HE capacity was accompanied by a reduction in funding and a possible decrease in the quality of teaching as well as a fall in the quality of the marginal student. Many contributions to the literature have noted a growing college wage premium over time. However, the role of the supply of college graduates in determining changes in the returns to a college education has been explored in comparatively few papers - mostly for US datasets. Two prominent US examples are Katz and Murphy (1992) and Taber (2001). The former assumes a simple linear trend change in demand and show that variations in the college premium can mostly be explained by variations in the supply of college graduates, while the latter favours an explanation based on an increase in the demand for unobserved skills rather than one based on an increase in the demand for skills accumulated in college. Card and Lemieux (2001) is also notable: they investigate the college premium in the US, Canada and the UK and find that the rise in the premium between 1980 and 1995 is confined to rises for younger workers which they argue is driven by falls in the growth of educational attainment that began with cohorts born in the 1950s.

Existing research on the role of supply is problematic because it relies on the variation in age participation rates associated with changes in demographics, which are inevitably relatively smooth, together with smooth assumptions about the demand side-usually it is assumed that there is

\footnotetext{
${ }^{1}$ Moreover, this period of higher education expansion was prior to the subsequent radical restructuring of higher education student funding that may have affected cohorts who are too young to appear in the data that we use here. The only significant change that took place over the period we consider was this large increase in the flow of new graduates into the labour market.

${ }^{2}$ The college drop-out rate for the UK is extremely low-so entry to HE almost invariably implies graduation.

${ }^{3}$ OECD (2007) data reveal, over the same period as the UK expansion, that Australia experienced a rise of $59 \%$, Finland $54 \%$, France $53 \%$, Ireland $81 \%$, Italy $53 \%$, New Zealand $101 \%$, Norway $82 \%$, and Spain $63 \%$.
} 
some exogenous and fixed rate of skill-biased technical change which increases the relative demand for college graduates linearly over time. The advantage of the suddenness and size of the UK HE supply-side change is that it is likely to swamp any possible changes in the demand side that occurred over this relatively short time period and so our results are not likely to be sensitive to particular assumptions made about demand.

Thus, our focus is on how the college premium has varied across time and, in particular, across cohorts. ${ }^{4}$ However, one difficulty for us is that the expansion of HE might have changed high-ability non-graduates into low-ability graduates. A second difficulty is that there was a corresponding reduction in per student resources over the expansion which may have reduced graduate quality at all levels of student ability because universities may have added less value. We attempt to distinguish these further effects of the expansion by estimating quantile regression models.

Section II explains the selection of our data and describes the characteristics of the sample used in our analysis. Section III presents results. In Section IV we conclude.

\section{The Data}

We use the large quarterly Labour Force Survey (LFS) cross-section datasets pooled from 1994 to $2006 .{ }^{5}$ Figure 1 shows the proportion of 25-59-year-

\footnotetext{
${ }^{4}$ Earlier research in the UK by Harkness and Machin (1999) and Gosling and Meghir (2000) suggests rising returns over time using data from the 1970s to the mid-1990s. Chevalier, Harmon, Walker and Zhu (2004), Walker and Zhu (2003), O'Leary and Sloane (2004, 2005) and McIntosh (2006) use more recent LFS data from 1993 to 2002 and show broadly constant returns on average. It is tempting to conclude that the results are consistent with a simple story whereby the growth in the supply of graduates just keeps pace with the growth in demand. However, Walker and Zhu (2003) and O'Leary and Sloane (2005) noted that the data seemed to show lower returns in recent years but they were limited in their ability to address the effects of the expansion because of the sparsity of the post-expansion data. Now that more time has elapsed we explore this feature in more detail in this paper with the latest available data.

${ }^{5}$ We drop those living in Scotland and Northern Ireland (which both have quite different education systems from England and Wales). Although LFS does not explicitly record where education took place, we also drop those recorded as having Scottish education qualifications. We drop those with zero or missing hours of work or earnings; and immigrants (who will mostly have been educated outside the UK). Our analysis is all conditional on being employed - we have no reliable data for the incomes of the self-employed and we do not take into account the effect of education on employment (which might be construed as an additional component of the return to education). We use the LFS-derived variable "hourpay", which is defined as the ratio of usual earnings to usual hours (from main job) including paid overtime. Similar results hold using the reported hourly wage in the data. However, only a small proportion of graduates report an hourly wage rate. We then drop observations in the top and bottom $1 \%$ of the hourly wage distribution within the group with a college degree and the group without by gender.
} 


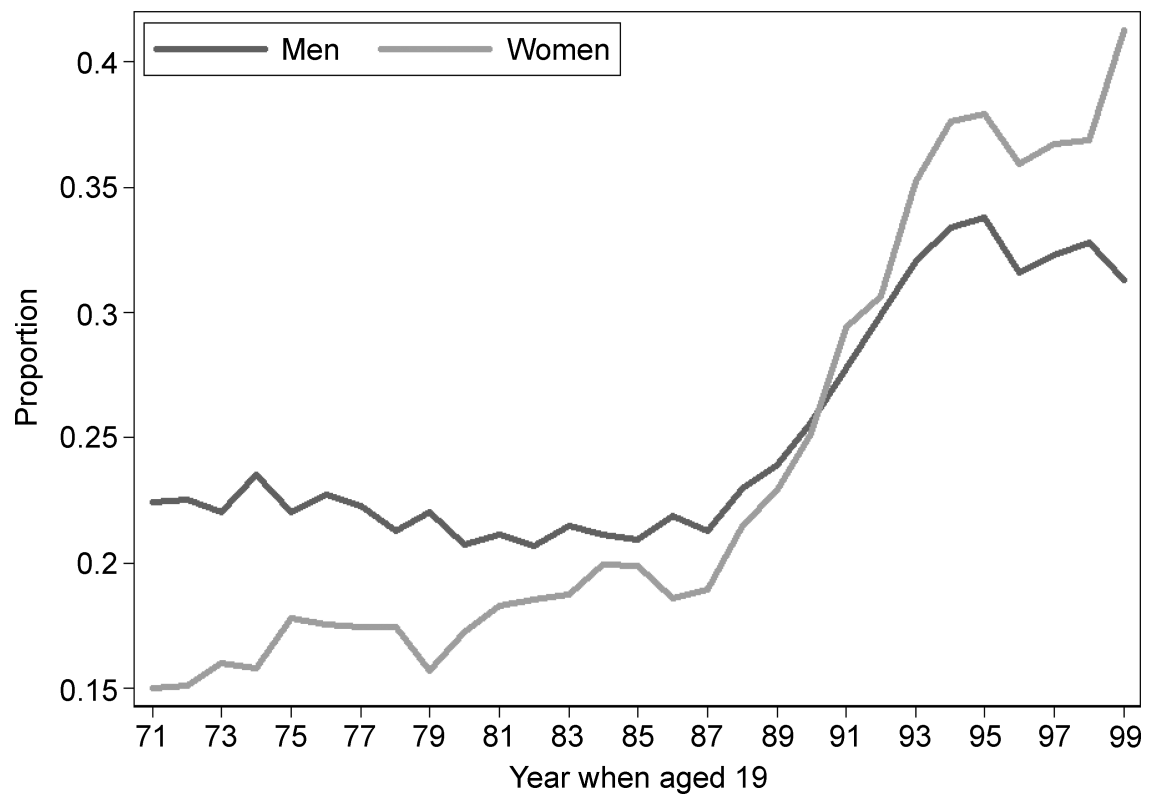

Fig. 1. Proportion of birth cohorts who record having a first degree

Source: UK quarterly Labour Force Survey, 1994-2006, authors' calculations. First degree is defined as an undergraduate bachelor degree. Birth cohort is defined here as the year at which the individual reached the age of 19 .

olds who have a degree in the whole LFS data, broken down by birth cohort. It is clear that there is a large rise in this proportion for men, from $21 \%$ for cohorts who were of college-going age (19) up to 1987 (i.e., birth cohorts up to 1968 ) to $32 \%$ by the time the 1974 birth cohort reaches 19 in 1993 (approximately a 50\% rise in the proportion of the flow). There is an even larger rise for women, from $18 \%$ to $36 \%$ (a $100 \%$ rise in the proportion). These are huge increases over a period of just six years. The LFS data show that the expansion clearly starts in 1987 and ends in 1993 and this matches the trends in the official statistics, which are based on the population of college entrants, very well. ${ }^{6}$

\footnotetext{
${ }^{6}$ See DfES (2007). The Age Participation Index (API), the percentage of each cohort currently undertaking higher education, was replaced in 2000 by the Higher Education Initial Participation Rate (HEIPR), for England, which counts the proportion of young people (1730) who have had at least six months' HE experience. The series are not consistent with each other but it seems likely that their trends will be quite similar. The main difference from our Figure 1 arises because our data use a sample of employed individuals - since graduates are more likely to be employed than non-graduates this leads our participation estimates to be larger. The position was broadly stable over the 1970s and 1980s but increased quickly from about $15 \%$ for men and $12 \%$ for women in 1988 , to $30 \%$ for men and women in 1994 ,
} 
In our analysis of the college premium we include observations of those who have a first (bachelor) degree together with those that left school, usually at the age of 18 , with at least the minimum qualifications required for consideration for admission to university-two "A(dvanced)-level" qualifications. ${ }^{7}$ That is, we drop individuals who would not have been able to gain admission to university even if they had wanted to attend. Finally, we drop observations under the age of 25 , because wages are very volatile soon after graduation, and drop those over the age of 37, because very few individuals over this age will have been likely to have entered college after the start of the expansionary phase. Throughout we distinguish between males and females. Our final sample consists of 11,270 male graduates vs 2,792 male non-graduates, and 10,695 female graduates vs 2,736 non-graduates. The numbers of observations by age and by cohort are shown in Table 1 . This table groups the data into three-year age ranges for three-year birth cohorts. It is clear that the data are not age balanced, and in our subsequent empirical analysis we rebalance the data by appropriate weighting. Thus, in Figures $2 \mathrm{a}$ and $2 \mathrm{~b}$ we present coefficients, and associated confidence intervals, from a parsimonious specification of log earnings equations that control only for whether an individual has some vocational qualification, and being non-white. It is clear that, while there is considerable volatility, because of the small cell sizes, there is no significant trend in the college premium. Thus, at first sight, these remarkable increases in supply have not dramatically affected wage differentials.

where the rates stabilised. The great majority of UK students who attend higher education do so soon after completing high school at the age of 18 or 19, and the great majority study full-time. This study is typically for a three-year first-degree (Bachelor) course (health, and some other, courses are typically longer). The main driver of the expansion of higher education in this period was the increase in the full-time participation of 18-21-year-olds. It is this growth, from $15 \%$ in 1988 to $30 \%$ in 1994, that is measured by the official API. In addition, there was some growth of mature students and of entrants taking alternative routes to higher education. An increasing proportion of graduates go on to take postgraduate courses. Since the HE expansion began in 1988 this corresponds to the cohort born around 1969, and the expansion had ceased for men around 1994 corresponding to the 1975 or 1976 birth cohorts. ${ }^{7}$ A-level qualifications, usually in three subjects, are normally examined at the end of a two-year spell of post-compulsory schooling between ages 16 and 18. Grades in these qualifications are used as criteria for university entry. A minimum of two passing grade A-levels is a necessary but not sufficient condition for entry. Many courses demand that particular subjects have been studied to A-level standard-for example, mathematics courses and most science courses will require mathematics to be amongst the A-level passes of applicants. Entry requirements differ considerably across institutions and degree courses but there is a well-developed applications system for matching students to courses and this ought to ensure that most students with two or more A-level passes can find a place on some course at some institution. Although we are mainly interested in the return to having an undergraduate first degree we also include in our sample for analysis all individuals who also have higher academic qualifications. 
Table 1. Sample sizes broken down by age groups and birth cohorts

\begin{tabular}{|c|c|c|c|c|c|}
\hline \multirow[b]{2}{*}{ Birth cohort groups } & \multicolumn{4}{|c|}{ Age group } & \multirow[b]{2}{*}{ Total } \\
\hline & $34-37$ & $31-33$ & $28-30$ & $25-27$ & \\
\hline \multicolumn{6}{|l|}{ Male } \\
\hline $1957-62$ & 1,630 & 244 & - & - & 1,874 \\
\hline $1963-65$ & 1,232 & 902 & 262 & - & 2,396 \\
\hline $1966-68$ & 1,076 & 888 & 835 & 228 & 3,027 \\
\hline 1969-71 & 735 & 784 & 844 & 673 & 3,036 \\
\hline $1972-74$ & 83 & 615 & 764 & 526 & 2,151 \\
\hline $1975-77$ & - & 69 & 572 & 526 & 1,167 \\
\hline $1978-80$ & - & - & 23 & 388 & 411 \\
\hline Total & 4,756 & 3,502 & 3,300 & 2,504 & 14,062 \\
\hline \multicolumn{6}{|l|}{ Female } \\
\hline 1957-62 & 1,204 & 203 & - & - & 1,407 \\
\hline $1963-65$ & 1,035 & 811 & 212 & - & 2,058 \\
\hline $1966-68$ & 961 & 816 & 777 & 203 & 2,757 \\
\hline 1969-71 & 659 & 770 & 829 & 682 & 2,940 \\
\hline $1972-74$ & 79 & 694 & 841 & 767 & 2,381 \\
\hline $1975-77$ & - & 76 & 683 & 625 & 1,384 \\
\hline 1978-80 & - & - & 37 & 467 & 504 \\
\hline Total & 3,938 & 3,370 & 3,379 & 2,744 & 13,431 \\
\hline
\end{tabular}

Note: The shaded area indicates the HE expansion period.

Source: UK quarterly Labour Force Survey, 1994-2006, authors' calculations. Birth cohort groups are defined by year of birth

\section{The Analysis}

The conventional approach to thinking about the role of supply in determining wage differentials is generally based on making simple assumptions about technology. For example, it is common to assume that there are two types of labour that enter a CES production function with a fixed elasticity of substitution between them. Then the evolution of the wage differential depends, via the inverse of the elasticity of substitution, on the race between relative demands and supplies. Goldin and Katz (2007) is a recent US example and they note that the annual rate of expansion of the US relative supply of college to non-college workers from 1980 to 2005 was just $2.26 \%$ p.a. and that the college premium increased by just $0.9 \%$ p.a. Given an assumed elasticity of substitution of 1.64, as in Katz and Autor (1999), the implication of this modest rise in the college premium was that, over this period, the rise in relative demand for college workers had to have been around $3.7 \%$ p.a.

If we adopted this estimate of US relative demand shift for the UK over the six-year expansion period then we would expect a relative demand rise of around $24 \%$. Our relative supply measure is similar to the US one 


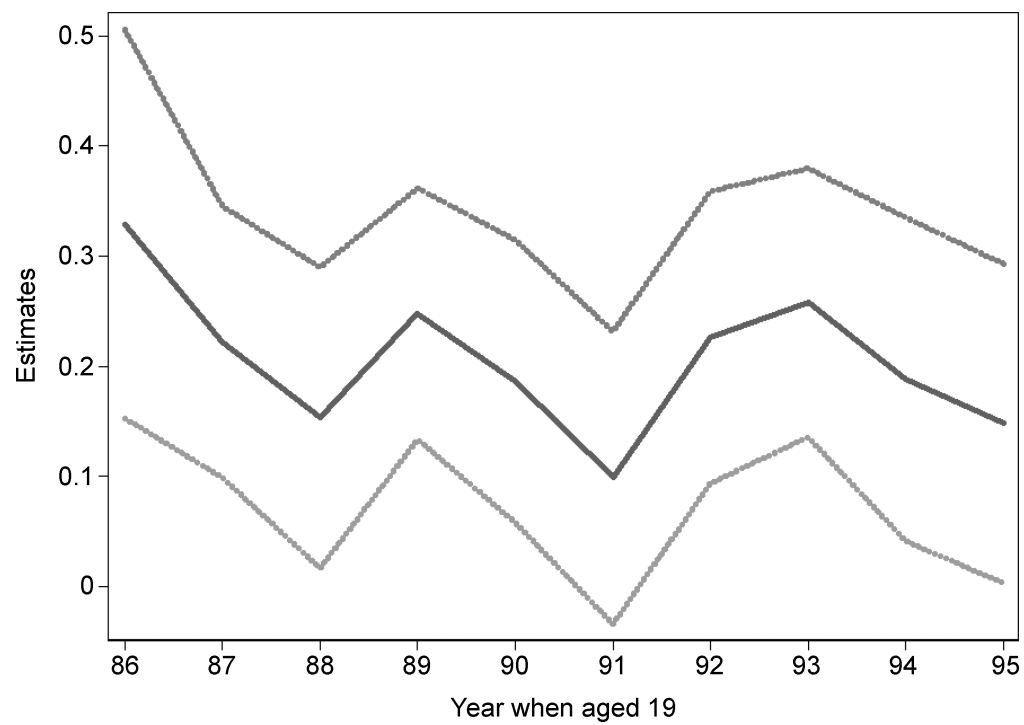

Fig. 2a. College premium and 95\% confidence interval for $25-27$-year-olds by year aged 19: males

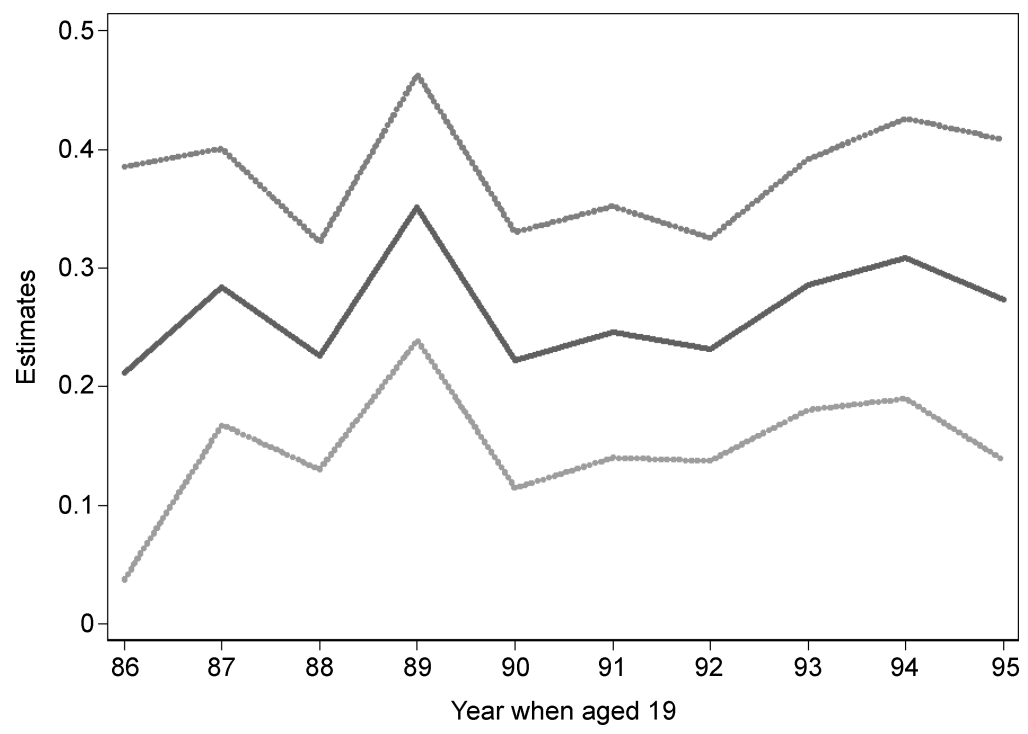

Fig. 2b. College premium and 95\% confidence interval for $25-27$-year-olds by year aged 19: females

Notes: Birth cohort is defined here as the year at which the individual reached the age of 19 . The dotted lines indicate the $95 \%$ confidence interval around the point estimates from cohort-specific sub-samples controlling for having vocational qualifications, being non-white, survey year, age and age squared. Observations are weighted so that age groups are balanced. 
Table 2. Crude difference-in-differences of changes in log wages

\begin{tabular}{lcc}
\hline & Male & Female \\
\hline Degree & 0.182 & 0.279 \\
& $(0.031)$ & $(0.032)$ \\
Young cohort & 0.007 & -0.066 \\
(i.e., born between 1975 and 1977) & $(0.056)$ & $(0.050)$ \\
Degree $*$ Young cohort & 0.001 & 0.105 \\
& $(0.062)$ & $(0.055)$ \\
\hline
\end{tabular}

Notes: Standard errors in parentheses. Comparison of sample of 28-30-year-olds born between 1966 and 1968 and between 1975 and 1977. Omitted category is born between 1966 and 1968 and with no degree. Observations are weighted so that age groups are balanced across the two cohorts.

and is the ratio of college graduates to non-graduates who have A-level qualifications ${ }^{8}$ (broadly speaking, these are high-school graduates who do not go to college). The expansion in this ratio in the UK, comparing the immediate pre- and post-expansion cohorts, was a rise of $50 \%$ from 3.76 to 5.67 for men, and a rise of $73 \%$ for women from 3.55 to 6.14 . If we also adopt the Katz and Autor assumption on the elasticity of substitution then we would infer from this rapid rise that the resulting college premium should experience a fall of around $15 \%$ for men and $29 \%$ for women. This is clearly not a feature of our preliminary results reported in Section II.

To pursue this further, we first compute crude difference-in-difference estimates, for those that went to college post the HE expansion compared to those that attended pre-expansion, for a narrow cohort group (1,407 men and 1,460 women, aged 28-30). The results of this are presented in Table 2. For women, whose expansion was largest, we find a $28 \%$ college premium $^{9}$ prior to the expansion. Post-expansion we estimate that A-level female wages fell in real terms by $6.6 \%$ while college female wages rose by $10.5 \%$, implying that the post-expansion female college premium rose by around $4 \%$. For men, the estimated college premium remains constant at $18 \%$ across the HE expansion period.

To refine this difference-in-differences analysis we take the micro data, collapse it into cells defined by birth cohort and age separately by gender, weight by cell sizes, and estimate the college premium by cohort group. The results of this analysis are shown in Table 3, which allows for the college premium to vary by cohort groups through the inclusion of interactions, controlling for age. The interaction terms are jointly insignificant. But comparing the immediate pre-expansion cohort (born 1966-1968) with the immediate post-expansion cohort (born 1975-1977) we see that the

\footnotetext{
${ }^{8}$ There was no significant change in the A-level wage premium over the period considered here.

${ }^{9}$ We refer to the log point difference as the premium. 
Table 3. Collapsed data estimates of the college premium and its changes across the HE expansion

\begin{tabular}{lcc}
\hline & Male & Female \\
\hline Degree & 0.146 & 0.401 \\
& $(0.045)$ & $(0.048)$ \\
Born 1963-65 & -0.045 & -0.012 \\
& $(0.036)$ & $(0.039)$ \\
Born 1966-68 & -0.075 & -0.029 \\
& $(0.047)$ & $(0.050)$ \\
Born 1969-71 & -0.165 & -0.100 \\
& $(0.061)$ & $(0.064)$ \\
Born 1972-74 & -0.210 & -0.177 \\
& $(0.078)$ & $(0.083)$ \\
Born 1975-77 & -0.242 & -0.239 \\
& $(0.095)$ & $(0.101)$ \\
Born 1978-80 & -0.246 & -0.276 \\
& $(0.114)$ & $(0.120)$ \\
Degree $*$ Born 1963-65 & 0.027 & 0.014 \\
& $(0.051)$ & $(0.054)$ \\
Degree $*$ Born 1966-68 & -0.027 & -0.004 \\
& $(0.066)$ & $(0.071)$ \\
Degree $*$ Born 1969-71 & -0.021 & 0.022 \\
& $(0.085)$ & $(0.091)$ \\
Degree $*$ Born 1972-74 & -0.032 & 0.045 \\
& $(0.109)$ & $(0.116)$ \\
Degree $*$ Born 1975-77 & -0.084 & 0.067 \\
& $(0.134)$ & $(0.142)$ \\
Degree $*$ Born 1978-80 & -0.099 & 0.113 \\
& $(0.159)$ & $(0.170)$ \\
$p$-Value (joint significance of interactions) & 0.827 & 0.920 \\
Observations & 336 & 336 \\
\hline
\end{tabular}

Notes: Standard errors in parentheses. Controls include cell proportions having any vocational qualification, non-white, survey year and age groups, as well as all of their interactions with degree. The omitted category is born between 1957 and 1962 and with no degree. The shaded area indicates the HE expansion period.

college premium for males fell by an insignificant $5.7 \%$, while for women we estimate a rise of $7.1 \%$, which is also insignificant.

An important difficulty in exploring the effects of the expansion is that $\mathrm{HE}$ in the UK was highly subsidised over the period considered here and access was rationed by school performance (A-level score) at age 18. Thus, expanding college enrolment will have resulted in some relaxation of the "tariffs" required for university entry. This will imply that the most able students who were previously unsuccessful in gaining entry to HE would, post-expansion, have been able to find a place. Thus, the ability distribution of both the non-graduate group and the graduate group are likely to have changed. In particular, it seems likely that there was an influx of new students into HE with lower ability relative to what was previously the case. 
The corresponding exodus of high-ability students from the non-graduate distribution will imply that the average ability of this group will also have fallen. We therefore might expect that the college premium might change differentially across the ability distribution.

Thus, our estimates may suffer from bias associated with omitted ability bias which is traditionally thought to bias the schooling coefficient upwards. There is some suggestion in the literature that ability bias approximately cancels out the bias associated with measurement error in schooling but there is a worry, in this context, that one or both of these sources of bias may be changing over time. ${ }^{10}$ In the traditional ability bias story earnings and schooling are determined by $w=\beta S+\alpha A+\varepsilon$ and $S=\gamma A+\zeta$, where $w$ is the $(\log )$ wage rate, $S$ is years of schooling, $A$ is "ability", $\varepsilon$ is uncorrelated with $S$ or with $A$, and $\zeta$ is uncorrelated with $\varepsilon$. That is, $\zeta$ and $w$ are correlated only through their joint dependence on $A$. However, $A$ is unobservable so least squares estimates of $\beta$ in $w=\beta S+\varepsilon$ will be biased such that $\operatorname{plim}\left(\beta_{O L S}\right)=\beta+\alpha\left(\sigma_{A S} / \sigma_{S}^{2}\right)$. If, as seems reasonable, $\gamma>0$ and $\sigma_{A S}>0$, and if $\alpha>0$, then $\beta_{O L S}>\beta$. That is, OLS estimates of $\beta$ capture the effects of both $S$ and unobservables that are correlated with both $S$ and $w$, such as $A$.

The expansion of HE is likely to result in $\sigma_{A S}$ falling since HE institutions would then be accepting individuals with lower unobserved skills, $A$. This results in a fall in the estimate of $\beta_{O L S}$ even if $\beta$ were constant - that is, we would expect the anticipated fall in the OLS estimate of the college premium $\left(\beta_{O L S}\right)$ in response to the supply of college graduates to appear to be even larger than the fall in the true effect $(\beta)$. The only way to reconcile the rise in college graduate supply with the absence of a fall in the OLS estimate of the college premium is if $\alpha$ were also rising. Of course $\alpha$, the return to unobserved skill, may not be constant. Indeed, much of the existing literature suggests that $\alpha$ has been rising as well as $\beta$. Thus, our estimates are consistent with the view that the return to unobserved skill has been rising in the UK.

To explore how the expansion affected the college premium we present estimates, ${ }^{11}$ using the micro data, by quartile of the conditional wage distribution. Our aim here is to explore the extent to which the college premium may have changed differentially. The principal results of our quantile regressions are graphed in Figures 3 and 4 for males and females, respectively. ${ }^{12}$ The estimates presented are changes in college premium relative to the

\footnotetext{
${ }^{10}$ It seems unlikely that the extent of measurement error in wages or education is changing because there have been no changes to the survey instrument over the period of the data.

${ }^{11}$ These results do not control for having a higher (i.e., post-bachelor) degree. Controlling for this separately makes no effective difference to the results.

${ }^{12}$ The analyses have the same controls as in Table 3. Full results are available from the authors on request.
} 


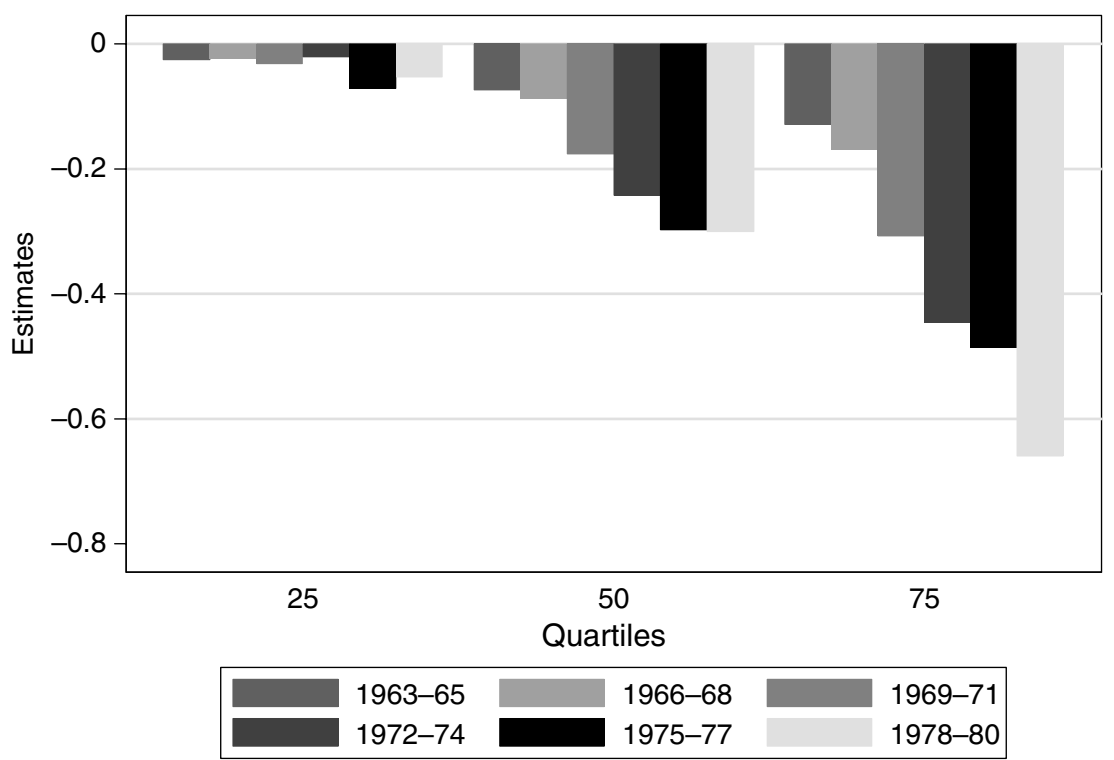

Fig. 3a. Wages and cohorts by quartiles: males with no college

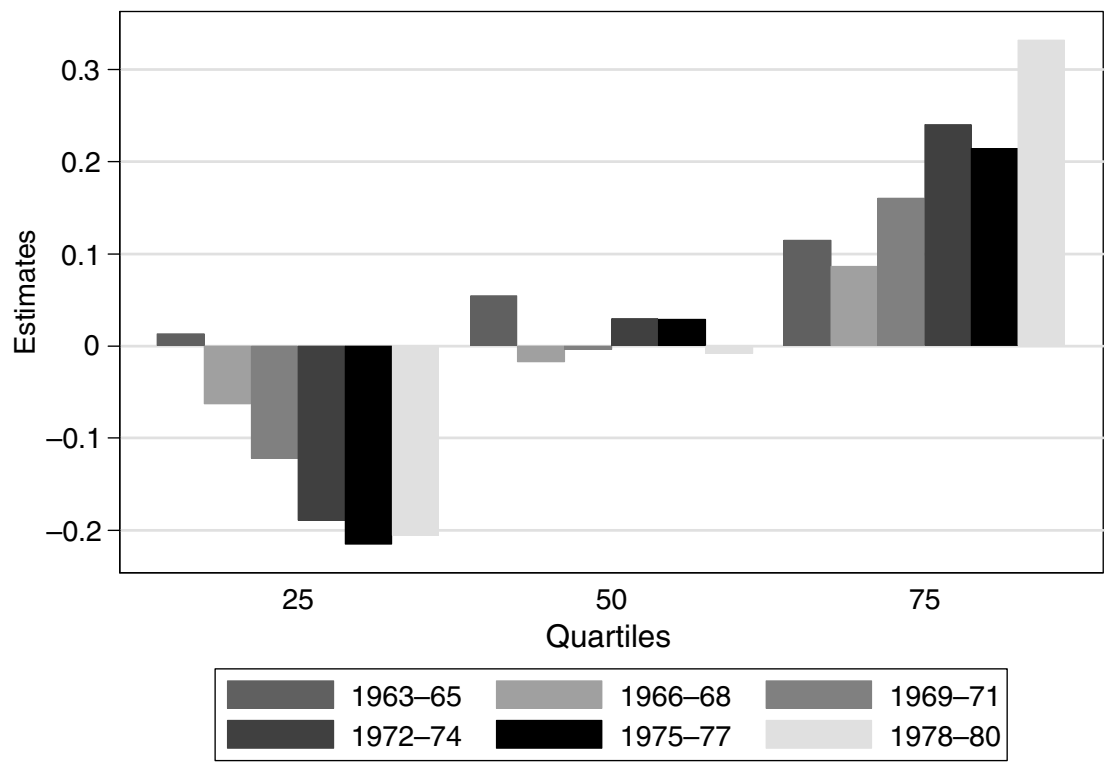

Fig. 3b. Wages and cohorts by quartiles: male college premium

Notes: Controls include cell proportions having any vocational qualification, non-white, survey year and age groups, as well as all of their interactions with degree. The omitted category is born between 1957 and 1962 and with no degree. Observations are weighted so that age groups are balanced across the birth cohorts. 


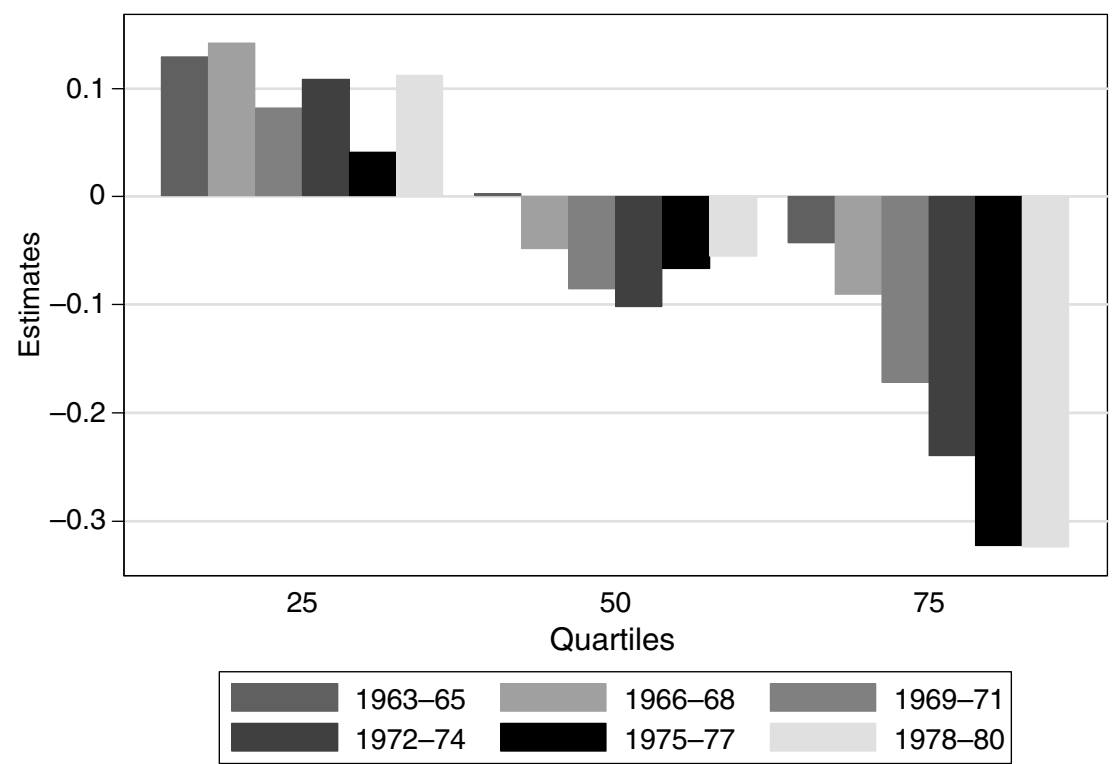

Fig. 4a. Wages and cohorts by quartiles: females with no college

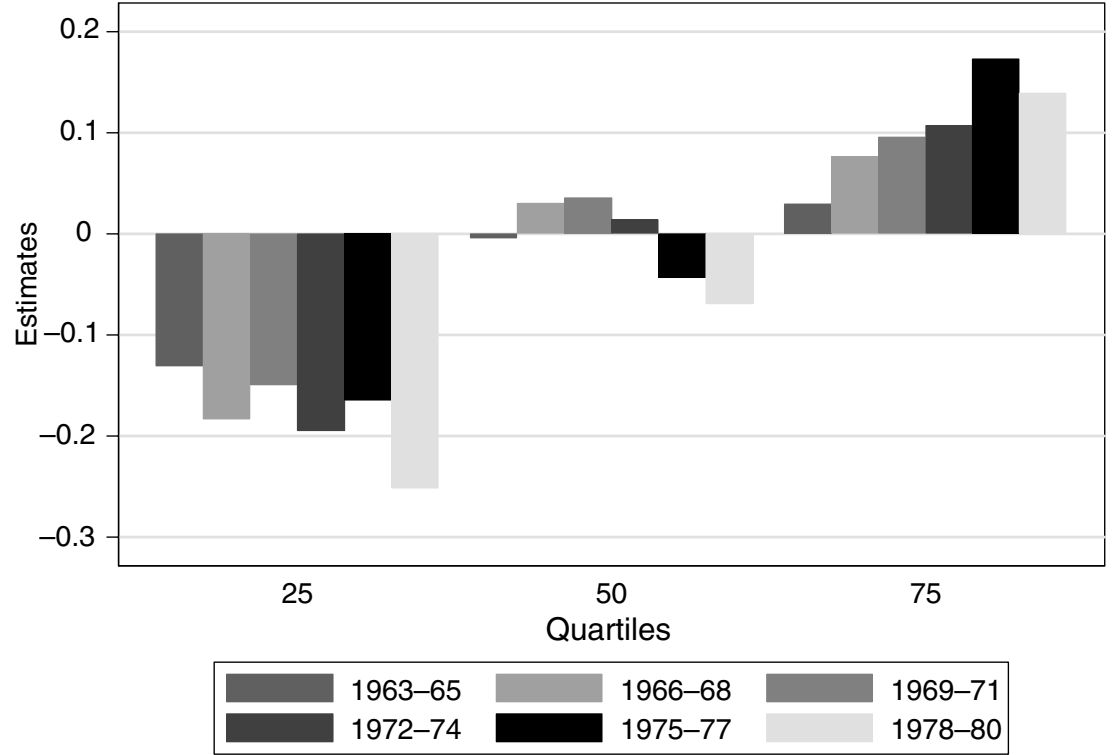

Fig. 4b. Wages and cohorts by quartiles: female college premium

Notes: Controls include cell proportions having any vocational qualification, non-white, survey year and age groups, as well as all of their interactions with degree. The omitted category is born between 1957 and 1962 and with no degree. Observations are weighted so that age groups are balanced across the birth cohorts.

(C) The editors of the Scandinavian Journal of Economics 2008. 
reference birth cohort. Part (a) of the figures show the cohort dummy coefficients alone and therefore show what has happened to non-college wages across successive cohorts by quartile. ${ }^{13}$ What is striking is the large fall in log wages across successive cohorts for the top quartiles of both men and women. Part (b) of the figures show the coefficients on the interactions between degree and cohort dummies and so shows how the college premium itself has varied across successive cohorts by quartile. The median regressions show some changes in the college premium but these are again not statistically significant for either males or females - comparing the immediately pre- and post-expansion cohorts (the second and second-to-last blocks) there is a $5 \%$ rise for males and $7 \%$ fall for females. In the top quartiles, for both males and females we see rises in the college premium-of $12 \%$ for males and $10 \%$ for females comparing across the same immediately pre- and post-expansion cohorts. In contrast, in the bottom quartile where the HE expansion will have been concentrated, we observe the male college premium does indeed fall across successive cohorts. For males in the bottom quartile, comparing the immediately pre- and post-expansion cohorts, there is a $15 \%$ fall in the premium (although this is again not statistically significant), which is consistent with our simple calibration exercise. However, for females in the bottom quartile we still find a small rise in the college premium - albeit only an insignificant $2 \%$ rise. ${ }^{14}$

Unfortunately, our data do not provide information on pre-college academic performance and we cannot therefore distinguish between the suggestion that the expansion was accompanied by a reduction in the ability of the marginal student, from the effects of financial resources not being increased in line with the expansion in student numbers. ${ }^{15}$ We might therefore expect the HE expansion to be accompanied by an overall decrease in teaching quality. One way of interpreting the effects of such a corresponding reduction in value-added is to imagine that post-expansion young college graduates are less than equivalent to pre-expansion young graduates. That is, the effective increase in the supply of skill associated with the HE expansion is less than is implied by a simple headcount of the flow of graduates. However, it seems very unlikely that this would be sufficiently large to eliminate the anachronistic rise in the college premium for high-ability men (and the very small fall for women).

\footnotetext{
${ }^{13}$ The omitted category for both Figures 3 and 4 is individuals born between 1957 and 1962 and with no degree. The college premia for this cohort group are 0.185 and $0.315 \log$ points for males and females, respectively.

${ }^{14}$ Inspection of the subject mix of men and women across cohorts shows only modest rises in the proportion of women choosing high return subjects - differences that are not large enough to explain this paradoxical rise in returns for women.

${ }^{15}$ The figures for funding per full-time equivalent student, in real terms, fell by $30 \%$ between 1987 and 1995. See DIUS (2002).
} 


\section{Conclusion}

Our analysis suggests, quite remarkably, that despite the large rises in HE participation in the late 1980 s through to the mid-1990s, there has been very little reduction in the college premium for men, on average. Indeed, we find that, despite the much larger increase in HE participation for women, there is a weakly significant $10 \%$ rise in their college premium comparing preand post-expansion groups controlling for age.

One explanation stems from considering the role of unobserved skills. It seems likely that the increase in HE participation was concentrated amongst those individuals with low unobserved skills - those with high unobserved skills were already very likely to be HE participants. Indeed we do find substantial rises in the estimated college premium for those in the top quartile of the residual wage distribution. This suggests that those who graduated from college and entered traditional "graduate" jobs, who we might think of as those with high unobserved skills, earned even larger returns ${ }^{16}$ than did earlier cohorts. In contrast, we do find a fall in the college premium for men in the bottom of the residual wage distributionand it is of a size that is consistent with a simple calibration exercise based on the findings of recent US research.

The implication of the results is that although the growth in the demand for observed skills was outstripped by supply over the HE expansion, there was a corresponding growth in demand for unobserved skills that, assuming that the supply of such skills is relatively fixed, will have increased the price of such skills $(\alpha)$ and hence increased the upward bias in OLS estimates of the price of observed skills $\left(\beta_{O L S}\right)$. It would be useful, in future work, to attempt to obtain IV estimates of $\beta$ that might, arguably, be free of ability bias to see if such estimates were depressed by the expansion of HE.

\section{References}

Card, D. and Lemieux, T. (2001), Can Falling Supply Explain the Rising Return to College for Young Men?, Quarterly Journal of Economics 116, 705-746.

Chevalier, A., Harmon, C., Walker, I. and Zhu, Y. (2004), Does Education Raise Productivity, or Just Reflect it?, Economic Journal 114, F499-F517.

DfES (Department for Education and Skills) (2007), Participation Rates in Higher Education, First Release SFR 10/2007, London.

DIUS (Department of Innovation, Universities and Skills) (2002), Statistical Bulletin: Education Training Expenditure, HMSO, London.

\footnotetext{
${ }^{16}$ The proportion of males in the bottom quartile of the residual wage distribution who are observed to have managerial and professional jobs fell from $50 \%$ in the immediate pre-expansion cohort to $28 \%$ in the immediate post-expansion cohort. For women the figures are $33 \%$ to $27 \%$.
} 
Goldin, C. and Katz, L. F. (2007), Long Run Changes in the US Wage Structure: Narrowing, Widening, Polarizing, NBER Working Paper no. 13568.

Gosling, A. and Meghir, C. (2000), The Changing Distribution of Male Wages in the UK, Review of Economic Studies 67, 635-666.

Harkness, S. and Machin, S. (1999), Graduate Earnings in Britain 1974-1995, Department for Education and Employment, Research Report no. 95, London.

Katz, L. F. and Autor, D. H. (1999), Changes in the Wage Structure and Earnings Inequality, in O. Ashenfelter and D. Card (eds.), Handbook of Labor Economics, Vol. 3a, NorthHolland, Amsterdam, 1463-1555.

Katz, L. and Murphy, K. (1992), Changes in Relative Wages, 1963-1987: Supply and Demand Factors, Quarterly Journal of Economics 107, 35-78.

McIntosh, S. (2006), Further Analysis of the Returns to Academic and Vocational Qualifications, Oxford Bulletin of Economics and Statistics 68, 225-251.

OECD (2007), Education at a Glance 2007, OECD, Paris.

O'Leary, N. C. and Sloane, P. J. (2004), The Return to a University Education in Great Britain, IZA Working Paper no. 1199.

O'Leary, N. C. and Sloane, P. J. (2005), The Changing Wage Return to an Undergraduate Education, IZA Working Paper no. 1549.

Taber, C. (2001), The Rising College Premium in the Eighties: Return to College or the Return to Unobserved Ability?, Review of Economic Studies 68, 665-691.

Walker, I. and Zhu, Y. (2003), Education, Earnings and Productivity-Recent UK Evidence, Labour Market Trends, March, 145-152. 